\title{
Cervical lymph node metastasis classified as regional nodal staging in thoracic esophageal squamous cell carcinoma after radical esophagectomy and three-field lymph node dissection
}

Junqiang Chen ${ }^{1 * \dagger}$, Sangang $\mathrm{Wu}^{2+}{ }^{2 \dagger}$ Xiongwei Zheng ${ }^{3}$, Jianji Pan ${ }^{1}$, Kunshou Zhu ${ }^{4}$, Yuanmei Chen ${ }^{4}$, Jiancheng Li ${ }^{1}$, Lianming Liao ${ }^{5}$, Yu Lin ${ }^{1}$ and Zhongxing Liao ${ }^{6}$

\begin{abstract}
Background: Lymph node metastasis (LNM) is most common in esophageal squamous cell carcinoma (SCC). The bi-directional spread is a key feature of LNM in patients with thoracic esophageal SCC (TE-SCC). The purpose of this study was to analyze the prognostic factors of survival in patients with TE-SCC with cervical lymph node metastasis (CLM) and validate the staging system of the current American Joint Committee on Cancer (AJCC) in a cohort of Chinese patients.
\end{abstract}

Methods: Of 1715 patients with TE-SCC who underwent radical esophagectomy plus three-field lymph node dissection at a single hospital between January 1993 and March 2007, 547 patients who had pathologically confirmed CLM (296 had surgery only and 251 had surgery + postoperative radiotherapy) were included in this study. The locations of the lymph nodes (LNs) were classified based on the guidelines of the Japanese Society for Esophageal Diseases.

Results: The rate of CLM was 31.9\% for all patients and was $44.2 \%, 31.5 \%$, and $14.4 \%$ for patients with upper, middle, and lower TE-SCC, respectively $(P<0.0001)$. The rates of metastasis to 101 (paraesophageal lymph nodes), 104 (supraclavicular lymph nodes), 102 (deep cervical lymph nodes) and 103 (retropharyngeal lymph nodes) areas were $89.0 \%, 25.6 \%, 3.7 \%$ and $0.5 \%$, respectively. The 5 -year overall survival (OS) rate with CLM was $27.7 \%$ (median survival, 27.5 months). The 5 -year OS rates were $21.3 \%$ versus 34.2\% (median survival, 21.9 months versus 35.4 months) for after surgery only versus surgery + postoperative radiotherapy, respectively $(P<0.0001$ for both). Multivariate analysis showed that the independent prognostic factors for survival were sex, pT stage, pN stage, number of fields with positive LNs, and treatment modality. In surgery only group, the 5 -year OS rates were $24.1 \%, 16.2 \%$ and $11.7 \%$, respectively, when there was metastasis to $101 \mathrm{LN}$ alone, $104 \mathrm{LN}$ alone or both $101 \mathrm{LN}$ and $104 \mathrm{LN}$. The 5-year OS rates were 17.7\%, 22.5\% and 31.7\%, for patients with upper, middle and lower TE-SCC, respectively $(P=0.112)$. The 5 -year OS rates were $43.0 \%$, 25.5\%, $10.2 \%$ in patients with 1 field (cervical LNs), 2 fields (cervical + mediastinal, and/or cervical + abdominal LNs), and 3 fields (cervical + mediastinal + abdominal LNs) positive $L N s$, respectively $(P<0.0001)$. The number of fields of positive LNs did not impact the OS according to different pN stage (all $P>0.05$ ).

(Continued on next page)

\footnotetext{
* Correspondence: junqiangc@163.com

${ }^{\dagger}$ Equal contributors

'Department of Radiation Oncology, The Teaching Hospital of Fujian Medical University, Fujian Provincial Cancer Hospital, 91 Maluding, Fuma Road,

Fuzhou, Fujian 350014, China

Full list of author information is available at the end of the article
} 
(Continued from previous page)

Conclusion: Patients with TE-SCC with CLM have better prognosis, which supports the current AJCC staging system for esophageal SCC.

Keywords: Esophageal cancer, Radiotherapy, Cervical lymph node metastasis, Prognosis, Tumor staging

\section{Background}

Lymph node metastasis (LNM) is most common in esophageal squamous cell carcinoma. The bi-directional or skip node spread is a key feature of LNM in patients with thoracic esophageal squamous cell carcinoma (TESCC), with a metastasis rate of $23.4-49.5 \%$ in the cervical node [1-4].

In the past two decades, advances in esophageal cancer surgery have been remarkable. Radical esophagectomy with extensive lymphadenectomy in the mediastinum, abdomen, and neck (so-called three-field lymphadenectomy, 3FL) has been the mainstay treatment for TESCC. The surgical approach can sufficiently expose the surgical field and completely dissect related lymph nodes with metastasis [1-5].

According to the Guidelines for Clinical and Pathologic Studies on Carcinoma of the Esophagus issued by the Japanese Society for Esophageal Diseases, the cervical lymph nodes (LNs) were classified into 101 (paraesophageal nodes), 102 (deep cervical nodes), 103 (retropharyngeal LNs), and 104 (supraclavicular LNs) areas. Each area is divided into left and right parts [6]. In the seventh edition of the American Joint Committee on Cancer tumor node metastasis (AJCC TNM) staging system for esophageal squamous cell carcinoma issued in 2009, LNs from the neck to the abdomen are defined as regional LNs. In the sixth edition AJCC TNM staging system, the subdivision of " $\mathrm{M}$ " classification into M1A and $\mathrm{M} 1 \mathrm{~B}$ according to the presence of nonregional LN involvement is not longer used [5]. In addition, whether metastasis to the cervical LNs, especially supraclavicular LNs (104), should be classified as local or distant metastasis has not be proposed. In the present retrospective study, the prognostic factors were analyzed in 547 patients with TE-SCC with cervical LNM after receiving extended esophagectomy with 3FL.

\section{Methods}

\section{Patient population}

From January 1993 to March 2007, 1715 consecutive patients with biopsy-proven TE-SCC were treated with 3FL at the Fujian Province Cancer Hospital, Fujian Medical University, Fuzhou, Fujian, China. Medical records of these patients were retrieved. Patients meeting the following criteria were selected for this study: (1) pathologically confirmed as squamous cell carcinoma of the esophagus and underwent extended esophagectomy plus
3FL, (2) the number of dissected LNs was $\geq 15$, (3) presurgical enhanced computed tomography scan did not reveal $\mathrm{LN}$ with a diameter $>1 \mathrm{~cm}$ in the cervical area (including supraclavicular area), (4) did not undergo chemotherapy and radiotherapy before esophagectomy and did not undergo chemotherapy after esophagectomy, and (5) did not have distant metastasis. According to the seventh edition of the AJCC TNM staging system released in 2009, $\mathrm{N}$ is subclassified based on the number of positive regional LNs (N1, 1-2 positive LNs; N2, 3-6 positive LNs; and N3, $\geq 7$ positive LNs) [5]. This study was performed in accordance with the Declaration of Helsinki and was approved by the ethics committee of Fujian Provincial Cancer Hospital. All patients provided written informed consent form for storage of their information in the hospital database and for using this information in this study. Of the 1715 patients, 547 patients were with cervical LNM, 296 patients underwent esophagectomy only, and 251 patients underwent radiotherapy after esophagectomy. The field of LNM was in accordance with the cervical, mediastinal, and abdominal LNs.

\section{Surgical procedures}

The resection of the thoracic esophagus was performed through a cervical incision, a right thoracotomy, and a laparotomy. Details of the procedure were described elsewhere [1]. According to the guidelines for clinical and pathologic studies on carcinoma of the esophagus issued by the Japanese Society for Esophageal Diseases, the cervical LNs were classified into 101 (paraesophageal nodes), 102 (deep cervical nodes), 103 (retropharyngeal lymph nodes) and 104 (supraclavicular nodes) areas. Each area is divided into left and right parts [6].

\section{Radiotherapy}

Patients underwent radiotherapy 3-4 weeks after esophagectomy. T-shaped fields were used. The T-shaped field included bilateral supraclavicular fossi, mediastinum, left gastric nodes, and the tumor bed. The medium total radiation dose consisted of 50 Gy for the tumor bed administered in 2 Gy of daily dose fractions, 5 fractions a week, over a period of 5 weeks [7].

\section{Follow-up}

Patients were instructed to undergo follow-up evaluations every 3 months for the first year, every 6 months for the next 2 years, and annually thereafter. As of May 
$1,2009,90.1 \%$ of the patients returned for follow-up according to the schedule. Survival status of patients who did not come at the scheduled follow-up times was updated through telephone calls or letters every 6 months. Survival status of patients who could not be reached in this manner was obtained through the Fujian Public Safety Bureau's registration center system. In total, 1336, 799 , and 447 patients were followed up for 1,3 , and 5 years, respectively.

\section{Statistical analysis}

Statistical analysis of group differences was performed using the Chi-square test for categorical variable data. Survival plots of patients were constructed using the Kaplan-Meier method and were compared using the log-rank test. A Cox regression proportional hazard multivariate analysis was performed to identify statistically significant factors associated with overall survival (OS). $P<0.05$ was considered to be statistically significant. All statistical analyses were performed using the software package SPSS 15.0.

\section{Results}

\section{Rate and pattern of LNM}

In total, 547 of the 1715 patients met the inclusion criteria. The mean number of dissected LNs was 25.8 (range, 15-73). The frequency of any LNM was 31.9\%. Specifically, the rates of cervical LNM for upper, middle, and lower TE-SCC were $44.2 \%, 31.5 \%$, and $14.4 \%$, respectively $(P<0.0001)$ (Table 1$)$. The rates of LNM to $101,104,102$, and 103 regions were $28.4 \%, 8.2 \%, 1.2 \%$, and $0.2 \%$, respectively. The rates of LNM from upper, middle, and lower TE-SCC to 101 and 104 were significantly different $(P<0.05)$ (Table 1$)$. For patients with cervical metastasis, the rates of LNM to 101, 104, 102, and 103 regions were $89.0 \%, 25.6 \%, 3.7 \%$, and $0.5 \%$, respectively.

\section{Relationship between cervical lymph node metastasis and survival}

The 3-year and 5-year survival rates for patients $(\mathrm{n}=$ 547) with LNM were $41.5 \%$ and $27.7 \%$, respectively. The median survival was 27.5 months. The 5 -year survival rates and the median survival times were $21.3 \%$ versus $34.2 \%$, and 21.9 months versus 35.4 months after surgery only $(\mathrm{n}=296)$ versus surgery plus postoperative radiotherapy $(\mathrm{n}=251)$, respectively $[P<0.0001$ for both, hazard ratio (HR) (95\% CI) 0.641 (0.521-0.788)] (Figure 1).

In surgery only group, the 5-year OS rates for patients' metastasis to $101 \mathrm{LN}$ alone, 104 LN alone or both 101 $\mathrm{LN}$ and $104 \mathrm{LN}$ were $24.1 \%, 16.2 \%$, and $11.7 \%$, respectively. The median survival times were 23.3 months, 20.0 months, and 17.7 months, respectively $[P=0.117$, HR (95\% CI) 1.129 (0.996-1.280)] (Figure 2). The 5-year OS for patients with upper, middle, and lower TE-SCC were $17.7 \%, 22.5 \%$, and $31.7 \%$, respectively. The corresponding median survival times were 17.3 months, 22.6 months, and 37.2 months, respectively $[P=0.112$, HR (95\% CI) 0.734 (0.549-0.980)] (Figure 3).

\section{Analysis of prognostic factors of survival}

Univariate analysis showed that sex, tumor length by $\mathrm{x}$ ray, $\mathrm{pT}$ stage, $\mathrm{pN}$ stage, the number of fields with positive LNs, and treatment modality were predictors for survival. Age, tumor location, and histopathological type were not statistically significant predictors of survival $(P>0.05)$ (Table 2).

Multiple Cox regression indicated that sex, pT stage, $\mathrm{pN}$ stage, the number of fields with positive LNs, and treatment modality were independent predictors for survival (Table 3).

\section{Survival of different fields of positive lymph nodes according to the $\mathrm{pN}$ stage}

The 5-year OS rates were $43.0 \%, 25.5 \%, 10.2 \%$ in patients with 1 field (cervical LNs), 2 fields (cervical + mediastinal, and/or cervical + abdominal LNs), and 3 fields

Table 1 Characteristics of LNM in 1715 patients with TE-SCC

\begin{tabular}{|c|c|c|c|c|c|c|}
\hline \multirow[b]{2}{*}{ Variable } & \multirow{2}{*}{$\begin{array}{l}\text { All } \\
\text { patients }\end{array}$} & \multicolumn{3}{|c|}{ Location of esophageal tumor } & \multirow[b]{2}{*}{$x^{2}$ Value } & \multirow[b]{2}{*}{$P$-value } \\
\hline & & Upper & Middle & Lower & & \\
\hline Number of patients (\%) & $1715(100)$ & $274(16.0)$ & $1281(74.7)$ & $160(9.3)$ & & \\
\hline \multicolumn{7}{|l|}{ Mean number of dissections } \\
\hline Nodes per patient (range) & $25.8(15-73)$ & $26.8(15-68)$ & $25.7(15-71)$ & $24.7(15-73)$ & & \\
\hline Number of positive CLM (\%) & $547(31.9)$ & $121(44.2)$ & $403(31.5)$ & $23(14.4)$ & 41.698 & $<0.0001$ \\
\hline Paraesophageal (101), n (\%) & $487(28.4)$ & $108(39.4)$ & $358(27.9)$ & $21(13.1)$ & 34.843 & $<0.0001$ \\
\hline Deep cervical (102), n (\%) & $20(1.2)$ & $7(2.6)$ & $12(0.9)$ & $1(0.6)$ & 5.575 & 0.062 \\
\hline Retropharyngeal (103), n (\%) & $3(0.2)$ & $2(0.7)$ & $1(0.1)$ & $0(0.0)$ & 5.802 & 0.055 \\
\hline Supraclavicular (104), n (\%) & $140(8.2)$ & $31(11.3)$ & $104(8.1)$ & $5(3.1)$ & 9.049 & 0.011 \\
\hline
\end{tabular}

Abbreviations: CLM cervical lymph node metastasis, LNM lymph node metastasis, TE-SCC thoracic esophageal squamous cell carcinoma. 


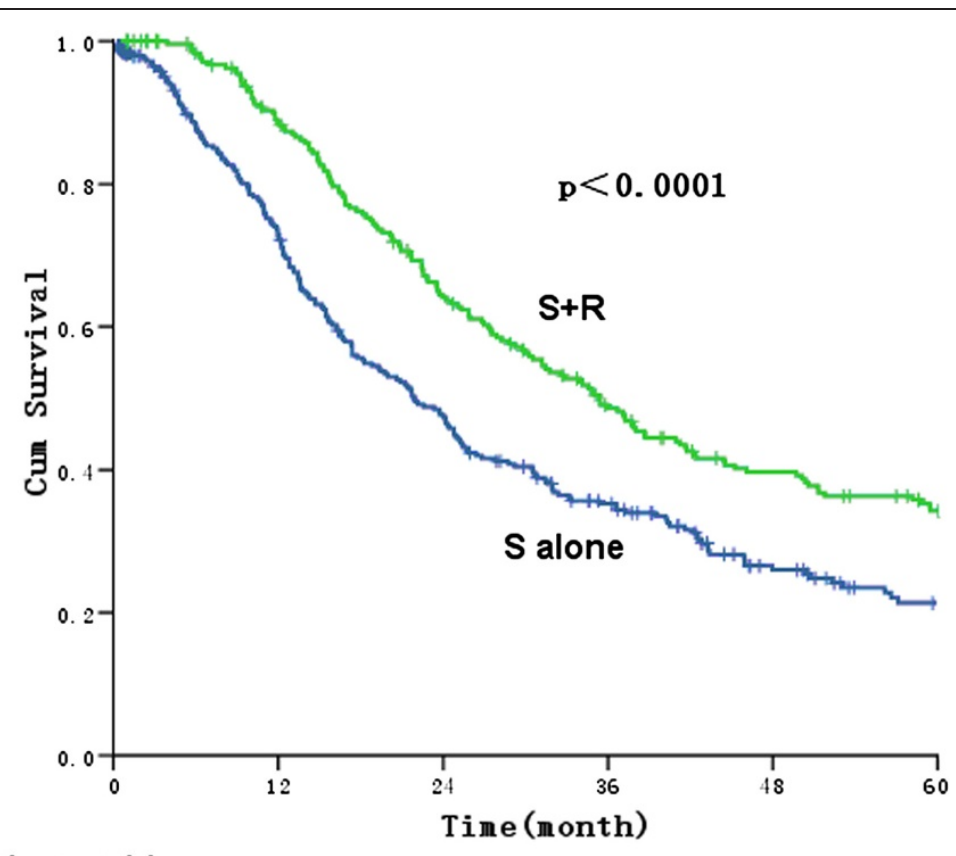

Patients at risk

$\begin{array}{lllcl}\text { S alone } & 296 & 195 & 83 & 29 \\ \text { S+R } & 251 & 208 & 106 & 65\end{array}$

Figure 1 Overall survival of patients who underwent surgery only ( $\mathrm{S}$, blue line) and who underwent surgery followed by radiation ( $\mathrm{R}+\mathrm{R}$, green line) for thoracic esophageal squamous cell carcinoma.

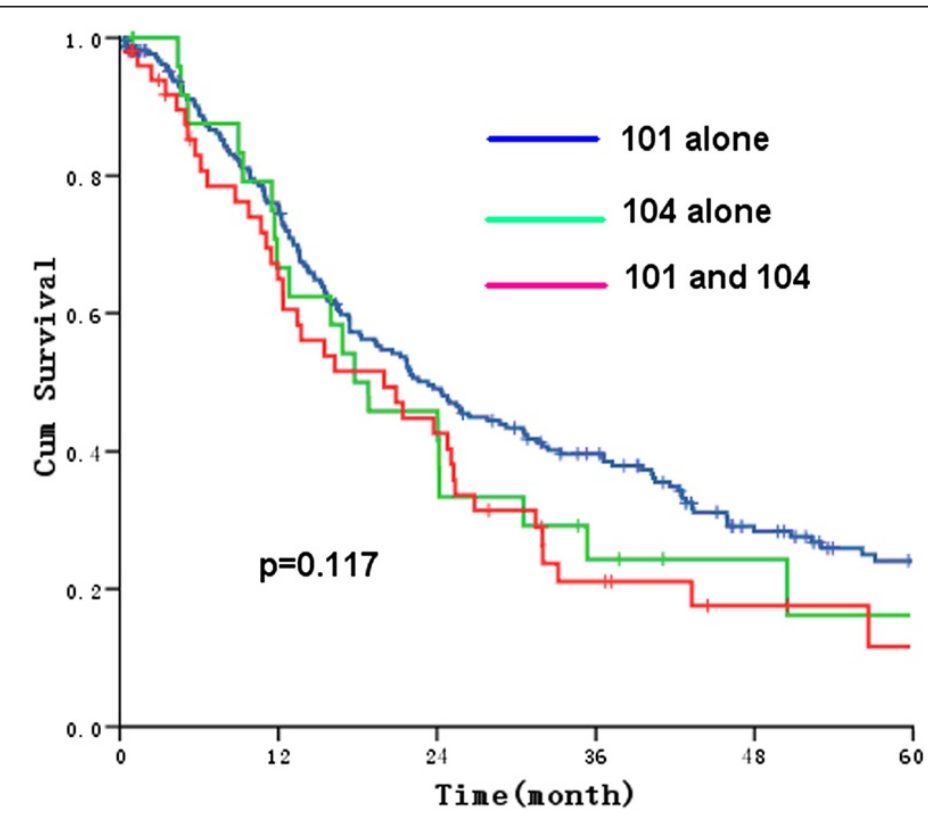

Patients at risk

$\begin{array}{lcccc}101 \text { alone } & 219 & 150 & 70 & 25 \\ 104 \text { alone } & 26 & 16 & 5 & 2 \\ 101 \text { and } 104 & 51 & 29 & 8 & 2\end{array}$

Figure 2 Overall survival of patients presenting with positive nodes in the 104 region (green line), the 101 region (blue line), and in both (red line) regions. 


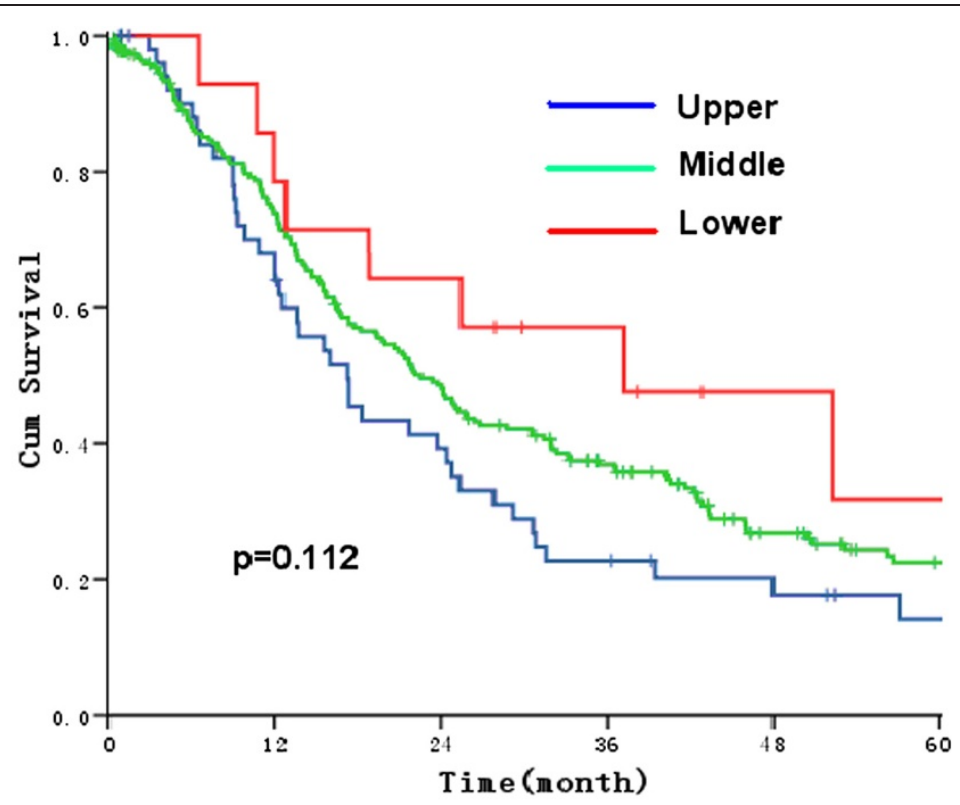

Patients at risk

$\begin{array}{llccc}\text { Upper } & 54 & 34 & 11 & 4 \\ \text { Middle } & 228 & 150 & 66 & 23 \\ \text { Lower } & 14 & 11 & 6 & 2\end{array}$

Figure 3 Overall survival of patients presenting with positive nodes in the lower region (i.e., middle and lower mediastinal and upper abdominal beds) (red line), the upper region (i.e., cervical and upper mediastinal beds) (blue line), and in the middle region (green line).

(cervical + mediastinal + abdominal $\mathrm{LNs}$ ) positive LNs, respectively $[P<0.0001$, HR $(95 \%$ CI $) 1.643$ (1.4371.878)] (Figure 4A). Subgroup analysis showed that the number of fields of positive LNs did not impact the OS according to different $\mathrm{pN}$ stage (all $P>0.05$ ) (Table 4 and Figure 4B-D). The OS between cervical + mediastinal positive LNs and cervical + abdominal positive LNs were not significantly different (Table 4 and Figure 5).

\section{Pattern of disease progression}

Postoperative radiotherapy reduced the recurrence rate of cervical and mediastinal LN compared with surgery alone $(P<0.05)$. The pattern of disease progression in patients with and without postoperative radiotherapy is shown in Table 5.

\section{Toxicity of postoperative radiotherapy}

Early toxicities related to postoperative radiotherapy were gastrointestinal reactions (swallowing pain and loss of appetite) accounting for $28.3 \%$ (71 patients), bronchitis (cough) accounting for 21.1\% (53 patients), and leukopenia accounting for $34.3 \%$ (86 patients, including 80 patients with grade $1-2$ and 6 patients with grade 3$)$.

Late toxicities were nonmalignant pleural effusion pericardial accounting for $2.4 \%$ (6 patients), radiationinduced pulmonary fibrosis accounting for $2.0 \%$ (5 patients), thoracic ulcer bleeding accounting for $1.2 \%$ (3 patients), anastomotic stricture accounting for $1.6 \%$ (4 patients), and anastomotic fistula accounting for $0.4 \%$ (1 patient).

\section{Discussion}

In the present study, pertinent results include that cervical LNM was the highest in patients with upper TE-SCC, followed by patients with middle and lower TE-SCC. Metastasis to paraesophageal nodes was most common. Metastasis to deep cervical nodes was less common. Metastasis to either retropharyngeal LNs or supraclavicular LNs was rare. The 5-year survival rates of patients undergoing surgery only were similar irrespective of whether there was metastasis to $101 \mathrm{LN}$ alone, 104 LN alone, or both $101 \mathrm{LN}$ and $104 \mathrm{LN}$. Multivariate factor analysis showed that the independent prognostic factors for survival were sex, $\mathrm{pT}$ stage, $\mathrm{pN}$ stage, the number of fields with positive LNs, and treatment modality. Cervical lymph node metastasis (CLM) was independent of tumor location.

There is controversy with regard to the prognostic significance and staging classification of cervical LNM in patients with TE-SCC. Most studies suggest that patients with cervical LNM have a better prognosis than those with hematogenous metastasis and thus cervical LNM should be included in " $N$ " instead of " $M$ " staging. Lerut 
Table 2 Univariate analysis of prognostic factors of survival in patients with TE-SCC with CLM

\begin{tabular}{|c|c|c|c|c|c|}
\hline \multirow[b]{2}{*}{ Variable } & \multirow[b]{2}{*}{ All (\%) } & \multirow{2}{*}{$\begin{array}{l}\text { 5-year } \\
\text { Survival rate (\%) }\end{array}$} & \multicolumn{2}{|c|}{ Median survival } & \multirow[b]{2}{*}{$P$-value } \\
\hline & & & (Months) & $\mathrm{X}^{2}$ value & \\
\hline Patients & $547(100)$ & 27.7 & & & \\
\hline Sex & & & & 8.323 & 0.004 \\
\hline Male & $406(74.2)$ & 24.6 & 24.8 & & \\
\hline Female & $141(25.8)$ & 37.0 & 39.5 & & \\
\hline Age (years) & & & & 0.225 & 0.635 \\
\hline$<60$ & $335(61.2)$ & 27.8 & 25.9 & & \\
\hline$\geq 60$ & $212(38.8)$ & 27.1 & 31.5 & & \\
\hline Thoracic tumor location & & & & 0.456 & 0.796 \\
\hline Upper & $121(22.1)$ & 31.7 & 29.2 & & \\
\hline Middle & $403(73.7)$ & 26.6 & 26.8 & & \\
\hline Lower & $23(4.2)$ & 23.3 & 25.5 & & \\
\hline Differentiation & & & & 1.623 & 0.444 \\
\hline Low & $118(21.6)$ & 23.4 & 24.1 & & \\
\hline Intermediate & $349(63.8)$ & 29.1 & 27.8 & & \\
\hline High & $80(14.6)$ & 28.6 & 28.3 & & \\
\hline Tumor length (cm) & & & & 7.638 & 0.006 \\
\hline$\leq 5$ & $283(51.7)$ & 31.7 & 32.0 & & \\
\hline$>5$ & $264(48.3)$ & 23.4 & 23.6 & & \\
\hline pT stage & & & & 20.517 & $<0.0001$ \\
\hline pT1 & $16(2.9)$ & 86.7 & 53.6 & & \\
\hline pT2 & $84(15.4)$ & 41.6 & 43.4 & & \\
\hline pT3 & $386(70.6)$ & 23.1 & 26.4 & & \\
\hline pT4 & $61(11.2)$ & 23.2 & 22.5 & & \\
\hline Number of nodal metastases & & & & 63.872 & $<0.0001$ \\
\hline $1-2$ & $226(41.3)$ & 43.3 & 49.7 & & \\
\hline $3-6$ & $221(40.4)$ & 20.3 & 23.5 & & \\
\hline$\geq 7$ & $100(18.3)$ & 9.9 & 16.7 & & \\
\hline Number of fields with positive lymph nodes ${ }^{a}$ & & & & 55.313 & $<0.0001$ \\
\hline 1 field & $191(34.9)$ & 43.0 & 43.3 & & \\
\hline 2 fields & $214(39.1)$ & 25.5 & 29.2 & & \\
\hline 3 fields & $142(26.0)$ & 10.2 & 19.3 & & \\
\hline Treatment program & & & & 18.145 & $<0.0001$ \\
\hline Surgery only & $296(54.1)$ & 21.3 & 21.9 & & \\
\hline Surgery + radiation & $251(45.9)$ & 34.2 & 35.4 & & \\
\hline
\end{tabular}

Abbreviations: CLM cervical lymph node metastasis, TE-SCC thoracic esophageal squamous cell carcinoma.

${ }^{\mathrm{a}} 1$ field (cervical lymph nodes), 2 fields (cervical + mediastinal, and/or cervical + abdominal lymph nodes), 3 fields (cervical + mediastinal + abdominal lymph nodes) with positive lymph nodes.

et al. reported that the 5-year OS for patients with positive LNs was $27.2 \%$ after 3FL in patients with middle TE-SCC [8]. Fang et al. reported that 5-year OS for patients with positive cervical nodes was $20.0 \%$ after $3 \mathrm{FL}$ with TE-SCC [9]. Tachimori et al. reported that 3-year OS for patients with positive cervical nodes was $43.8 \%$ after 3FL with TE-SCC [10]. Hsu et al. enrolled 488 patients who underwent primary curative resection without neoadjuvant therapy for esophageal cancer between 1995 and 2006. They found the 3-year OS rate was $35.4 \%$. The 3 -year OS rate was equivalent among patients in N1 (23.3\%), M1a (22.0\%), and nonregional LNM-related M1b (18.5\%). No survival difference was noted (18.5\%). However, differences in survival rate were evident between patients with and without distant metastasis $(P<0.001)$ [11]. Kato et al. reported that in 
Table 3 Multivariate analysis of prognostic factors of survival in patients with TE-SCC with CLM

\begin{tabular}{llllll}
\hline Variable & Regression coefficient B & SE & Wald value & HR (95\% Cl) & P-value \\
\hline Sex (male vs. female) & -0.294 & 0.127 & 5.342 & $0.745(0.581-0.956)$ & 0.021 \\
Tumor length $(\leq 5 \mathrm{~cm}$ vs. $>5 \mathrm{~cm})$ & 0.202 & 0.106 & 3.651 & $1.224(0.995-1.505)$ & 0.056 \\
pT category $(\mathrm{T} 1,2,3,4)$ & 0.283 & 0.096 & 8.687 & $1.327(1.100-1.602)$ & 0.003 \\
Number of nodal metastases $(1-2,3-6, \geq 7)$ & 0.332 & 0.102 & 10.533 & $1.393(1.140-1.702)$ & 0.001 \\
Fields of LNM (1 field, 2 fields, 3 fields) & 0.203 & 0.100 & 4.109 & $1.225(1.007-1.490)$ & 0.043 \\
Treatment program (surgery only vs. surgery + radiation) & -0.414 & 0.107 & 15.025 & $0.661(0.536-0.815)$ & $<0.0001$ \\
\hline
\end{tabular}

patients who underwent 3FL, the survival of patients with cervical LNM was significantly better than that of patients with hematogenous metastasis $(P=0.002)$. In patients without hematogenous metastases, the survival curve for the patients with histologic cervical LNM did not significantly differ from that of patients with mediastinal or abdominal LNM [12]. Rice et al. also found that the survivals were similar between patients in $\mathrm{M} 0$ classification and M1 classification $(P<0.0001)$. However, the survivals were significantly different between patients in M1a subclassification and M1b subclassification $(P=0.9)$ [13].

The results from the current study are similar to those reported by other researchers and support the current AJCC staging system which considers cervical LN to be regional LN [8-12]. The patients with cervical LN metastasis are classified as one group according to the AJCC staging system, and there is no explicit deliberation on whether the LNs adjacent to the cervical esophagus and supraclavicular LNs should be included. However, the cervical LN metastasis is classified elaborately into four groups including cervical esophageal LNs, cervical posterior deep LNs, retropharyngeal LNs, and supraclavicular LNs by the Japanese Society for Esophageal Diseases, though there was no published report on the prognosis related to this classification on cervical LNM. In the present study, the patients who underwent surgery only were classified into three groups, group of cervical esophageal LN metastasis, group of supraclavicular LN metastasis, and group of both cervical esophageal and supraclavicular LN metastasis. The stratified analysis on these three groups indicated that there was no significant difference in terms of 5-year survival rate, with the rate of $24.1 \%, 16.2 \%$, and $11.7 \%$, respectively $(P=0.117)$. These findings were in accordance with the concept defined by the AJCC staging system (seventh edition) that all cervical LN metastasis shall be regarded as one common regional $\mathrm{LN}$ metastasis.

In the present study, the 5-year survival rates in the postoperational radiotherapy group and surgery only group were $34.2 \%$ and $21.3 \%$, respectively $(P<0.0001)$. The improvement in survival rate by postoperational radiotherapy might be due to blood vessels, lymphatic vessels, and surrounding organs, exposure of the lower cervical area is challenging during esophagectomy and complete removal of LNs is sometimes impossible, which will cause recurrence after surgery. Postoperative radiotherapy will reduce metastasis and increase survival [14].

It was widely believed that the number of fields of cervical LN metastasis was a vital factor for prognosis of thoracic esophageal carcinoma $[13,15]$, which was consistent with the results of the present study that the number of fields of cervical LN metastasis was an independent factor of prognosis. The further stratified analysis indicated that the number of fields of cervical LN metastasis and survival rate were not significantly different among the patients with different numbers of positive LNs $(P>0.05)$, and the possible underlying reason might be that the number of positive LNs is

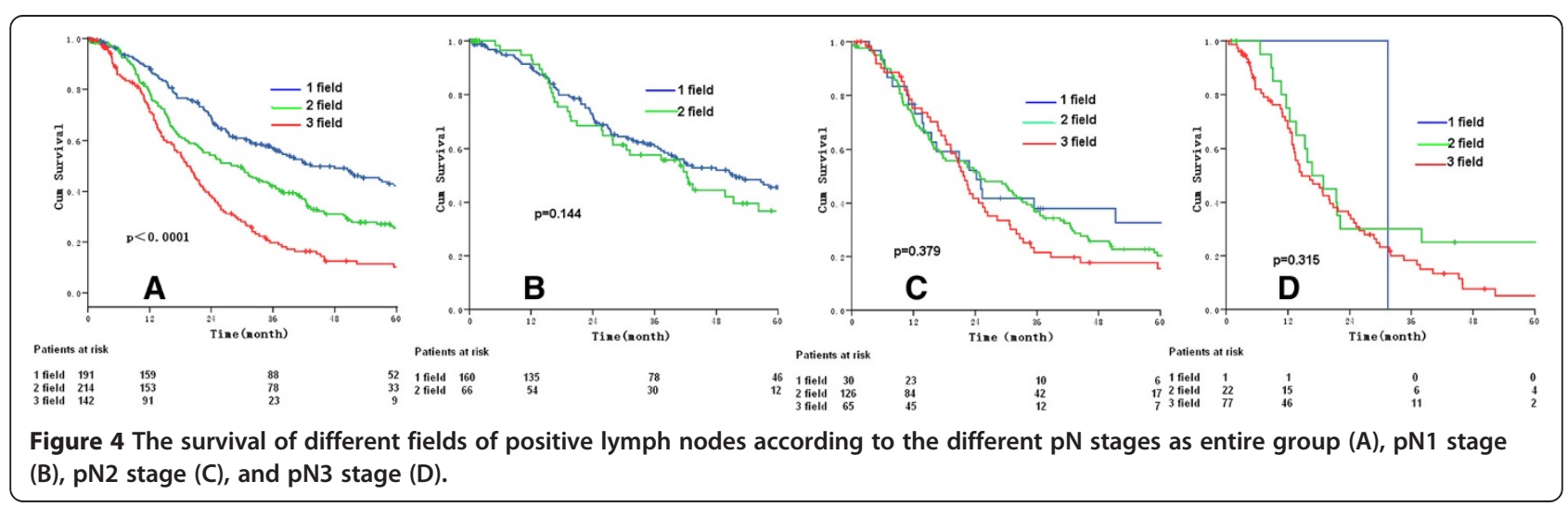


Table 4 Survival of different fields of positive lymph nodes according to the pN stage

\begin{tabular}{|c|c|c|c|c|c|}
\hline Variable & All (\%) & $\begin{array}{l}\text { 5-year } \\
\text { Survival rate (\%) }\end{array}$ & $\begin{array}{l}\text { Median survival } \\
\text { Time (months) }\end{array}$ & $x^{2}$ value & $P$-value \\
\hline $\mathrm{pN1}$ & & & & 2.136 & 0.144 \\
\hline 1 field & $160(29.3)$ & 45.6 & 51.8 & & \\
\hline 2 fields & $66(12.1)$ & 36.8 & 42.3 & & \\
\hline pN2 & & & & 1.940 & 0.379 \\
\hline 1 field & $30(5.5)$ & 32.6 & 24.2 & & \\
\hline 2 fields & $126(23.0)$ & 20.3 & 24.9 & & \\
\hline 3 fields & 65 (11.9) & 15.5 & 21.9 & & \\
\hline pN3 & & & & 2.311 & 0.315 \\
\hline 1 field & $1(0.2)$ & 0.0 & 31.5 & & \\
\hline 2 fields & $22(4.0)$ & 25.0 & 16.7 & & \\
\hline 3 fields & $77(14.1)$ & 5.1 & 14.7 & & \\
\hline Fields of LNM & & & & 0.154 & 0.695 \\
\hline$C+M$ & $163(76.2)$ & 23.7 & 25.9 & & \\
\hline$C+A$ & $51(23.8)$ & 30.1 & 34.0 & & \\
\hline
\end{tabular}

Abbreviations: A, abdominal; C, cervical; LNM, lymph node metastasis; M, mediastinal.

${ }^{a} 1$ field (cervical lymph nodes), 2 fields (cervical + mediastinal, and/or cervical + abdominal lymph nodes), 3 fields (cervical + mediastinal + abdominal lymph nodes) with positive lymph nodes.

Abbreviations: $\mathrm{Cl}=$ confidence interval; $\mathrm{CLM}=$ cervical lymph node metastasis; $\mathrm{HR}=$ hazard ratio; LNM, lymph node metastasis; $\mathrm{SE}=$ standard error; TE-SCC = thoracic esophageal squamous cell carcinoma.

correlated to the number of fields of metastasis, implying that the number of positive LNs is the most critical factor for prognosis instead of number of fields of metastasis.

\section{Conclusion}

This study demonstrates that patients with TE-SCC with cervical LNM have a better prognosis. Five-year survival in patients with TE-SCC with metastasis to paraesophageal

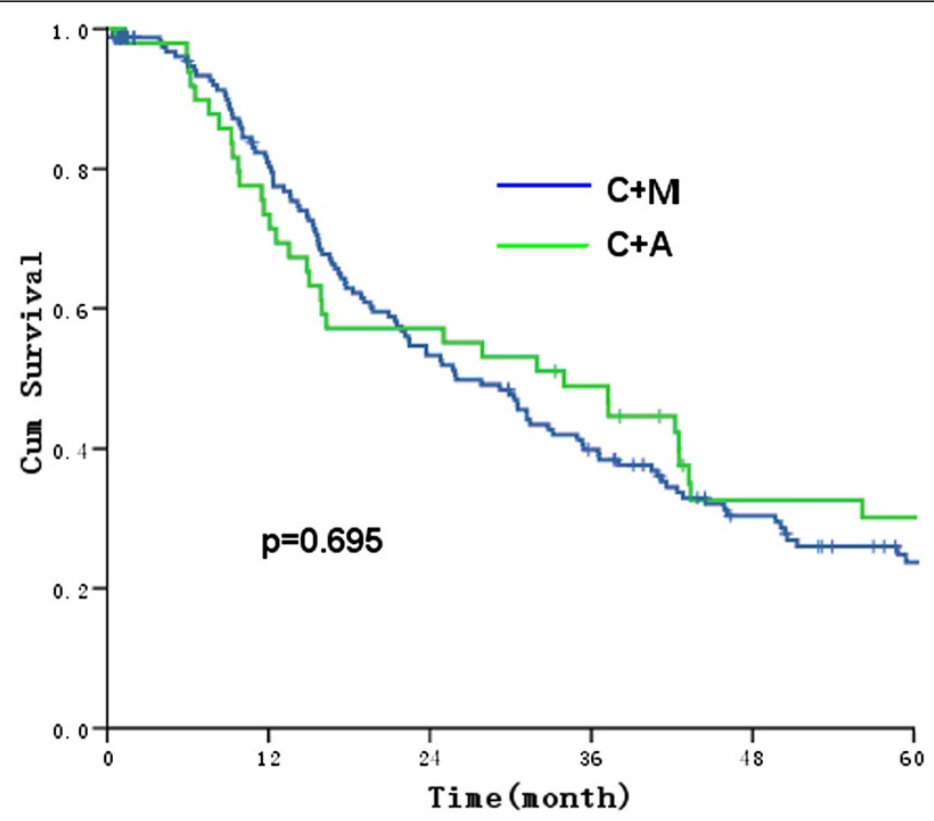

Patients at risk

$\begin{array}{lrrrr}1 \text { field } & 163 & 117 & 55 & 21 \\ 2 \text { field } & 51 & 36 & 23 & 12\end{array}$

Figure 5 The survival of patients with positive lymph node between cervical + mediastinal group and cervical + abdominal group. 
Table 5 Pattern of disease progression

\begin{tabular}{|c|c|c|c|c|}
\hline Variable & $\begin{array}{l}\text { Surgery } \\
(n=296)(\%)\end{array}$ & $\begin{array}{l}\text { Surgery + } \\
\text { postoperative } \\
\text { radiotherapy } \\
(n=251)(\%)\end{array}$ & $\mathrm{x}^{2}$ value & $P$-value \\
\hline \multicolumn{5}{|c|}{ Site of lymph node metastasis } \\
\hline $\begin{array}{l}\text { Cervical } \\
\text { lymph nodes }\end{array}$ & $42(14.2)$ & $13(5.2)$ & 12.192 & $<0.0001$ \\
\hline $\begin{array}{l}\text { Mediastinal } \\
\text { lymph nodes }\end{array}$ & $23(7.8)$ & $9(3.6)$ & 4.318 & 0.038 \\
\hline $\begin{array}{l}\text { Abdominal } \\
\text { lymph nodes }\end{array}$ & $10(3.4)$ & $13(5.2)$ & 1.094 & 0.296 \\
\hline Tumor bed & $6(2.0)$ & $2(0.8)$ & 1.426 & 0.2326 \\
\hline $\begin{array}{l}\text { Distant } \\
\text { metastasis }\end{array}$ & $70(23.6)$ & $57(22.7)$ & 0.067 & 0.795 \\
\hline $\begin{array}{l}\text { Locoregional } \\
\text { and distant } \\
\text { recurrence }\end{array}$ & $126(42.6)$ & $93(37.1)$ & 1.721 & 0.190 \\
\hline
\end{tabular}

nodes was similar to those with metastasis to supraclavicular LNs and supports the staging system of the current AJCC for esophageal squamous cell carcinoma that classifies cervical LN as regional LN. These patients will benefit from postoperative radiotherapy. Further perspective studies are needed to validate the conclusion.

\section{Abbreviations}

3-FL: Three-field lymphadenectomy; AJCC: American Joint Committee on Cancer; CLM: Cervical lymph node metastasis; LN: Lymph node; LNM: Lymph node metastasis; TE-SCC: Thoracic esophageal squamous cell carcinoma; TNM: Tumor-nodes-metastasis.

\section{Competing interests}

The authors declare that they have no competing interests.

\section{Authors' contributions}

JQC and SGW designed the study. JQC, XWZ, and JJP provided the databases. KSZ, YL, YMC,JCL, LML, and ZXL assembled and analyzed the data. JQC and SGW wrote the manuscript. All authors read and approved the final manuscript.

\section{Acknowledgement}

The authors thank the patients and their families and all the investigators, including the physicians, nurses, and laboratory technicians in this study.

\section{Author details}

${ }^{1}$ Department of Radiation Oncology, The Teaching Hospital of Fujian Medical University, Fujian Provincial Cancer Hospital, 91 Maluding, Fuma Road, Fuzhou, Fujian 350014, China. ${ }^{2}$ Xiamen Cancer Center, Department of Radiation Oncology, the First Affiliated Hospital of Xiamen University, Xiamen 361003, China. ${ }^{3}$ Departments of Pathology, The Teaching Hospital of Fujian Medical University, Fujian Provincial Cancer Hospital, Fuzhou 350014, China. ${ }^{4}$ Departments of Surgery, The Teaching Hospital of Fujian Medical University, Fujian Provincial Cancer Hospital, Fuzhou 350014, China. ${ }^{5}$ Center of Oncology Research, Academy of Integrative Medicine, Fujian University of Traditional Chinese Medicine, Fuzhou 350014, China. ${ }^{6}$ Department of Radiation Oncology, The University of Texas M. D. Anderson Cancer Center, Unit 97, 1515 Holcombe Boulevard, Houston, TX, USA.

Received: 2 July 2014 Accepted: 15 December 2014

Published: 19 December 2014

\section{References}

1. Chen J, Liu S, Pan J, Zheng X, Zhu K, Zhu J, Xiao J, Ying M: The pattern and prevalence of lymphatic spread in thoracic oesophageal squamous cell carcinoma. Eur J Cardiothorac Surg 2009, 36(3):480-486.

2. Akiyama $H$, Tsurumaru M, Udagawa H, Kajiyama Y: Radical lymph node dissection for cancer of the thoracic esophagus. Ann Surg 1994, 220(3):364-372. discussion 372-3.

3. Ando N, Ozawa S, Kitagawa Y, Shinozawa Y, Kitajima M: Improvement in the results of surgical treatment of advanced squamous esophageal carcinoma during 15consecutive years. Ann Surg 2000, 232(2):225-232.

4. Kato $H$, Igaki $H$, Tachimori $Y$, Watanabe $H$, Tsubosa $Y$, Nakanishi $Y$ : Assessment of cervical lymph node metastasis in the staging of thoracic esophageal carcinoma. J Surg Oncol 2000, 74(4):282-285.

5. Edge SB, Byrd DR, Compton CC: AJCC cancer staging manual. 7th edition. New York: Springer; 2009.

6. Japanese Society for Esophageal Diseases: Clinicopathological aspects. In: Guidelines for clinical and pathologic studies on carcinoma of the esophagus. 9th edition. Tokyo: Kanehara \& Co., Ltd; 1999:1-34.

7. Chen J, Zhu J, Pan J, Zhu K, Zheng X, Chen M, Wang J, Liao Z: Postoperative radiotherapy improved survival of poor prognostic squamous cell carcinoma esophagus. Ann Thorac Surg 2010, 90(2):435-442

8. Lerut T, Nafteux P, Moons J, Coosemans W, Decker G, De Leyn P, Van Raemdonck D, Ectors N: Three-field lymphadenectomy for carcinoma of the esophagus and gastroesophageal junction in $174 \mathrm{R} 0$ resections: impact on staging, disease-free survival, and outcome: a plea for adaptation of TNM classification in upper-half esophageal carcinoma. Ann Surg 2004, 240(6):962-972. discussion 972-974.

9. Fang WT, Feng J, Mao T, Fu SJ, Chen WH: Clinical implications of the new TNM staging system for thoracic esophageal squamous cell carcinoma. Zhonghua Zhong Liu Za Zhi 2011, 33(9):687-691 [Article in Chinese].

10. Tachimori $Y$, Kato H, Watanabe H, Yamaguchi H: Neck ultrasonography for thoracic esophageal carcinoma. Ann Thorac Surg 1994, 57(5):1180-1183.

11. Hsu WH, Hsu PK, Hsieh CC, Huang CS, Wu YC: The metastatic lymph node number and ratio are independent prognostic factors in esophageal cancer. J Gastrointest Surg 2009, 13(11):19131920.

12. Kato $H$, Igaki $H$, Tachimori $Y$, Watanabe $H$, Tsubosa $Y$, Nakanishi $Y$ : Assessment of cervical lymph node metastasis in the staging of thoracic esophageal carcinoma. J Surg Oncol 2000, 74(4):282-285.

13. Rice TW, Blackstone EH, Rybicki LA, Adelstein DJ, Murthy SC, DeCamp MM, Goldblum JR: Refining esophageal cancer staging. J Thorac Cardiovasc Surg 2003, 125(5):1103-1113.

14. Chen J, Pan J, Zheng X, Zhu K, Li J, Chen M, Wang J, Liao Z: Number and location of positive nodes, postoperative radiotherapy, and survival after esophagectomy with three-field lymph node dissection for thoracic esophageal squamous cell carcinoma. Int J Radiat Oncol Biol Phys 2012, 82(1):475-482.

15. Shimada H, Okazumi S, Matsubara H, Nabeya $Y$, Shiratori T, Shimizu T, Shuto K, Hayashi H, Ochiai T: Impact of the number and extent of positive lymph nodes in 200 patients with thoracic esophageal squamous cell carcinoma after three-field lymph node dissection. World J Surg 2006, 30(8):1441-1449.

doi:10.1186/1471-2482-14-110

Cite this article as: Chen et al:: Cervical lymph node metastasis classified as regional nodal staging in thoracic esophageal squamous cell carcinoma after radical esophagectomy and three-field lymph node dissection. BMC Surgery 2014 14:110. 